\title{
Impact of fibroblast activation protein on osteosarcoma cell lines in vitro
}

\author{
LIXIANG DING ${ }^{1-3}$, LIN YE ${ }^{1,2}$, JIANLI XU ${ }^{3}$ and WEN G. JIANG ${ }^{1,2}$ \\ ${ }^{1}$ Cardiff University-Capital Medical University Joint Centre for Biomedical Research; ${ }^{2}$ Metastasis and Angiogenesis \\ Research Group, Institute of Cancer and Genetics, Cardiff University School of Medicine, Cardiff CF14 4XN, UK; \\ ${ }^{3}$ Department of Orthopaedic Surgery, Beijing Shijitan Hospital, Capital Medical University, Beijing 100038, P.R. China
}

Received May 30, 2013; Accepted December 6, 2013

DOI: $10.3892 / \mathrm{ol} .2014 .1788$

\begin{abstract}
Fibroblast activation protein (FAP) or seprase, which belongs to the group type II integral serine proteases, is an integral membrane serine peptidase. Previous studies have demonstrated that FAP has an effect on tumor growth, proliferation and invasion. However, the cellular functional role that FAP plays in osteosarcoma (OS) remains unknown. The aim of the present study was to investigate the activities of FAP in OS cell lines. The gene expression of FAP was knocked down through a hammerhead ribozyme transgene, and the various functions between the knockdown cells and their control cells were tested using a series of functional assays in vitro. The results indicated that knockdown of FAP markedly reduced the ability of cellular growth, matrix adhesion, migration and invasion in MG-63 and HOS cell lines compared with the control cells $(\mathrm{P}<0.05)$. In conclusion, FAP influences OS cells and may play a role in OS tumor progression and metastasis.
\end{abstract}

\section{Introduction}

Osteosarcoma (OS) is the most prevalent form of aggressive primary malignant bone tumor with a high tendency to metastasize to the lung and occurs mainly in children and adolescents (1). Current optimal treatment consists of systemic multi-agent chemotherapy and surgical resection. The prognosis of OS patients has been markedly improved with the current optimal treatment. However, cases with metastases or an unresectable tumor have a poor prognosis. Therefore, there is a strong demand for early diagnosis and an improved therapeutic approach, which requires a comprehensive understanding of the molecular and cellular mechanisms of the disease. Human fibroblast activation protein (FAP, or seprase)

Correspondence to: Professor Wen G. Jiang, Metastasis and Angiogenesis Research Group, Institute of Cancer and Genetics, Cardiff University School of Medicine, Heath Park, Cardiff CF14 4XN, UK

E-mail: jiangw@cf.ac.uk

Key words: fibroblast activation protein/seprase, osteosarcoma, proliferation, adhesion, motility is a $170-\mathrm{kDa}$ homodimeric glycoprotein consisting of two 97-kDa subunits. FAP is an integral transmembrane protein belonging to the prolyl peptidase family with gelatinase and collagenase activity $(2,3)$. Human FAP gene is located on chromosome 2 q23 and the 760-aa FAP protein shows $48 \%$ sequence identity with dipeptidyl peptidase 4 (DPP-IV). FAP is expressed by reactive stromal fibroblasts in $>90 \%$ of common types of human epithelial cancer, in the granulation tissue of healing wounds and in bone and soft tissue sarcomas (4-6). FAP and DPP-IV are known to form a hetero-oligomer in a proteolytic complex, which is involved in the invasion of tumor cells in collagenous matrices (7). Increasing evidence has suggested that the expression of the membrane-bound FAP in various solid tumors is associated with tumor growth and invasion and poor prognosis (2,8-12). This makes FAP an attractive subject when seeking a tumor biomarker or a potential therapeutic target for the disease (13). To date, the function of FAP in OS cells and implication in the disease progression remain unknown.

The current study sought to investigate the expression of FAP in OS cell lines and examine the association of this molecule with OS cell function. A FAP-knockdown cell model using hammerhead ribozymes was used to study the function of FAP in vitro.

\section{Materials and methods}

Immunohistochemical staining of FAP.Immunohistochemistry staining method of avidin-biotin complex (ABC) was used to test the protein expression of FAP in tissue sections. Paraffin samples of OS bone tissues $(n=13)$ were sectioned (6- $\mu \mathrm{m}$ thick) and dewaxed using a series of gradient alcohol washes. Endogenous peroxidase activity was blocked with $0.3 \%$ hydrogen peroxide for $15 \mathrm{~min}$ prior to washes. Sections were then boiled, in a microwave, in antigen retrieval solution ( $\mathrm{pH}$ 6.0) to retrieve antigen. Following washing in Tris-buffered saline (TBS) three times, the horse serum (Vector Laboratories, Ltd., Peterborough, UK) was added and the sections were incubated at room temperature for $30 \mathrm{~min}$. The primary antibody (mouse anti-human FAP; 1:100; Santa Cruz Biotechnology, Inc., Santa Cruz, CA, USA), secondary antibody (multilink swine anti-mouse immunoglobulin) and ABC (Vector Laboratories, Ltd.) were added successively with 30, 30 and $45 \mathrm{~min}$ of incubation, respectively, and three TBS 
washes were performed in between. Absence of the primary antibody was used as a negative control. Diaminobenzidine chromogen (Vector Laboratories, Ltd.) was added to the sections and incubated in the dark for $5 \mathrm{~min}$. Sections were then counterstained in Gill's hematoxylin and dehydrated in ascending grades of methanol prior to clearing in xylene and mounting under a cover slip. Monoclonal mouse FAP $\alpha$ (ss-13; sc-100528) and anti-GAPDH (sc-32233) were obtained from Santa Cruz Biotechnology, Inc. Peroxidase-conjugated anti-mouse was purchased from Sigma-Aldrich (Poole, UK).

Cell culture. OS cell lines, HOS and MG-63, were purchased from the European Collection of Animal Cell Cultures (Salisbury, UK). The cells were routinely cultured in Dulbecco's modified Eagle's medium/Ham's F12 with L-Glutamine medium (PAA Laboratories, Yeovil, UK), supplemented with the antibiotics, penicillin and streptomycin and $10 \%$ fetal calf serum (PAA Laboratories) and incubated at $37.0^{\circ} \mathrm{C}, 5 \% \mathrm{CO}_{2}$ and $95 \%$ humidity.

Generation of FAP knockdown in OS cell lines. Anti-human FAP hammerhead ribozymes were designed based on the structure of FAP mRNA, generated using the Zuker RNA mFold program (14). The ribozymes were synthesized and cloned into a pEF6/V5-His-TOPO plasmid vector (Invitrogen Life Technologies, Paisley, UK). Ribozyme transgenes and empty pEF6 control plasmids were transfected into HOS and MG-63 cells individually, according to a previously reported procedure $(15,16)$. Following transfection and blasticidin $(5 \mu \mathrm{g} / \mathrm{ml})$ selection, cells were subsequently cultured in medium with blastidin $(0.5 \mu \mathrm{g} / \mathrm{ml})$ to maintain the transfectants. The ribozyme transgene plasmids containing cells were routinely tested to confirm the knockdown of FAP expression at cDNA or protein level. Cells transfected with anti-FAP ribozyme and empty plasmid vector were respectively labeled as HOS ${ }^{\text {FAPRIB }}$ and $\mathrm{HOS}^{\mathrm{pEF}}$ for HOS cells and MG-63 $3^{\text {FAPRIB }}$ and MG-63 ${ }^{\text {pEF6 }}$ for the transfected MG-63 cells.

RNA extraction and reverse transcription-polymerase chain reaction ( $R T-P C R)$. RNA was extracted from cells using the TRI reagent (Sigma-Aldrich). RT was performed using the iScript $^{\mathrm{TM}}$ cDNA synthesis kit (Bio-Rad, Hercules, CA, USA). The following PCR conditions were used: Denaturing at $94^{\circ} \mathrm{C}$ for $40 \mathrm{sec}$; annealing at $55^{\circ} \mathrm{C}$ for $40 \mathrm{sec}$; and extension at $72^{\circ} \mathrm{C}$ for $60 \mathrm{sec}$. PCR was conducted over 30 cycles with an initial 5 min denaturing step $\left(94^{\circ} \mathrm{C}\right)$ and a final 10 min extension step $\left(72^{\circ} \mathrm{C}\right)$. PCR products were separated on a $2 \%$ agarose gel stained with ethidium bromide. The primer sequences used are provided in Table I.

SDS-PAGE and western blotting. Proteins of each control or transfected cells were obtained following lysis. Equal amounts of each sample were separated on a $10 \%$ acrylamide gel. Following transfer from the gel onto a nitrocellulose membrane (Santa Cruz Biotechnology, Inc.), proteins were probed using the respective primary antibodies (FAP and GAPDH) at a concentration of 1:300, and specific peroxidase-conjugated secondary antibodies at a concentration of 1:1,000. Protein bands were documented using a gel documentation system (UVITech Ltd., Cambridge, UK).
In vitro growth assay. Briefly, 2,000 cells were seeded into each well using three 96-well plates labeled as Day 1, 3 and 5. Following incubation for 1, 3 and 5 days, cells were fixed in 4\% (v/v) formaldehyde and stained with $0.5 \%$ (w/v) crystal violet. The crystal violet stain was then extracted using $10 \%(\mathrm{v} / \mathrm{v})$ acetic acid and cell density was determined by measuring the absorbance at a wavelength of $540 \mathrm{~nm}$ using an ELx800 spectrophotometer (BioTek Instruments, Inc., Winooski, VT, USA).

In vitro Matrigel invasion assay. In the in vitro Matrigel invasion assay (17), a 24-well plate with Transwell inserts containing 8.0- $\mu \mathrm{m}$ pores (Becton-Dickinson, Franklin Lakes, NJ, USA) was first coated with $50 \mu \mathrm{g}$ /insert of Matrigel matrix basement membrane (BD Biosciences, Oxford, UK). In total, 15,000 cells were seeded into Transwell inserts, followed by $72 \mathrm{~h}$ of incubation. After three days of incubation, cells which had invaded through the artificial basement membrane to the outside of the Transwell insert were fixed, stained and counted.

In vitro Matrigel adhesion assay. In the in vitro Matrigel adhesion assay (18), a 96-well plate was precoated with $5 \mu \mathrm{g}$ Matrigel per well. Briefly, 45,000 cells were seeded into each well. Following $45 \mathrm{~min}$ of incubation, non-adherent cells were removed by vigorous washing using TBS. Adherent cells were then fixed, stained and counted.

In vitro migration/wound-healing assay. In the in vitro migration/wound-healing assay (19), a total of 40,000 cells were seeded in a 24-well plate and, upon reaching confluence, the medium was changed and the monolayer was scraped with a fine gauge needle to create a wound. The plate was placed on a heated plate to maintain a constant temperature of $37^{\circ} \mathrm{C}$. Images of the cells were captured following wounding and every 15 min during $1.5 \mathrm{~h}$ with a digital camera (GXCAM-5; GT Vision Ltd., Suffolk, UK) attached to a microscope (Leitz DMIRB; Leica Microsystems Ltd., Buckinghamshire, UK) at x200 magnification.

Electric cell-substrate impedance sensing (ECIS)-based cellular motility assay. The 9600 model of the ECIS instrument (Applied BioPhysics, Inc., Troy, NY, USA) was used for attachment (adhesion) using a 96W1E plate, as well as a motility assay (wounding assay) (20-22). ECIS measures the interaction between cells and the substrate to which the cells are attached via gold-film electrodes placed on the surface of culture dishes. Following a stabilization, the same number of $\mathrm{HOS}^{\mathrm{wt}}, \mathrm{HOS}^{\mathrm{pEF} 6}, \mathrm{HOS}^{\mathrm{FAPrib}}, \mathrm{MG}^{\mathrm{wt}}, \mathrm{MG}^{\mathrm{pEF} 6}$ or $\mathrm{MG}^{\mathrm{FAPrib}}$ $(80,000$ per well) in the same volume of medium $(200 \mu \mathrm{l})$ were added to each well. During the initial $3 \mathrm{~h}$ when cells were attaching to the bottom of the wells, impedance and resistance of the cell layer were recorded for the attachment ability analysis. After $10 \mathrm{~h}$, when confluence was reached, the monolayer was electrically wounded at $6 \mathrm{~V}$ for $30 \mathrm{sec}$. Impedance and resistance of the cell layer were immediately recorded for a period of $\leq 20 \mathrm{~h}$ for the motility ability analysis.

Statistical analysis. Experimental procedures were repeated independently at least three times. Statistical analysis was performed using the Minitab statistical software package (version 14; Minitab, Ltd., Coventry, UK). The two-sample 
Table I. Primers used for polymerase chain reaction.

Primer sequence, 5'-3'

Optimal annealing temperature, ${ }^{\circ} \mathrm{C}$

\begin{tabular}{clr}
$\begin{array}{c}\text { FAP ribozyme } \\
\text { 2F }\end{array}$ & & \\
CR & ACTAGTAAATTAGCATATGTCTATCAAAACAATATTTCGTCCTCAGGACT & 55 \\
FAP & & 55 \\
F1 & TCCCTTGCTAATTCAAGTGT & 55 \\
R1 & AGAGCTTTAGCAATCTGTGC & 55 \\
F2 & TGGAAAATGATTTGAAAAAT & 55 \\
R2 & CTGTGTAGACAGACGCGTAA & 55 \\
GAPDH & & 55 \\
F8 & GGCTGCTTTTAACTCTGGTA & 55 \\
R8 & GACTGTGGTCATGAGTCCTT & \\
\hline
\end{tabular}

FAP, fibroblast activation protein.

t-test was used for normally distributed data, and data are presented as the mean \pm standard error of the mean. $\mathrm{P}<0.05$ was considered to indicate a statistically significant difference.

\section{Results}

Expression of FAP in OS cell lines and tissues. The presence of FAP was evident in the two human OS cell lines (HOS and MG-63) tested through RT-PCR (Fig. 1A). To investigate the biological function of FAP in OS, these cell lines were selected for knockdown studies.

To assess the expression pattern of FAP at the protein level, immunohistochemical staining of FAP was performed in the human OS tissues. Using a specific anti-FAP monoclonal antibody, FAP was detected in the cytoplasm of tumor cells, but was absent from osteocytes in the background bone tissues (Fig. 1B).

Manipulation of FAP expression by ribozyme transgene. RT-PCR results demonstrated that FAP mRNA expression was successfully knocked down in $\mathrm{HOS}^{\text {FAPrib }}$ and $\mathrm{MG}^{\text {FAPrib }}$ cells in comparison with the level of expression in empty plasmid cells $\left(\mathrm{HOS}^{\mathrm{pEF} 6}\right.$ and $\mathrm{MG}^{\mathrm{pEF}}$; Fig. 2A and $\mathrm{B}$ ). Additionally, western blotting was used to probe for FAP protein levels in the control and transfected cell lines. Similar to the trends observed at the mRNA level, FAP protein was found to be highly expressed in all the control cell lines $\left(\mathrm{HOS}^{\mathrm{WT}}, \mathrm{MG}^{\mathrm{WT}}\right.$, $\mathrm{HOS}^{\mathrm{pEF} 6}$ and $\left.\mathrm{MG}^{\mathrm{pEF} 6}\right)$ and expression of FAP protein exhibited a marked reduction in the transfected cell lines $\left(\operatorname{HOS}^{\mathrm{FAPrib}}\right.$ and $\mathrm{MG}^{\text {FAPrib}}$ ) (Fig. 2C and D).

Knockdown of FAP reduces $O S$ cell growth. The in vitro tumor growth assay was used for the detection of change in growth caused by FAP knockdown in HOS and MG-63 cells. The same result was observed between these two cell lines when the growth rates were analyzed following a total 5-day incubation, which was that absence of FAP caused a low growth rate in OS cells, compared with their control
A 55 
A
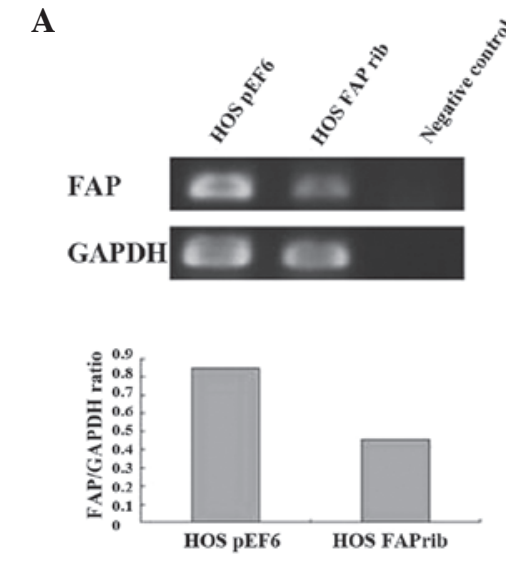

C

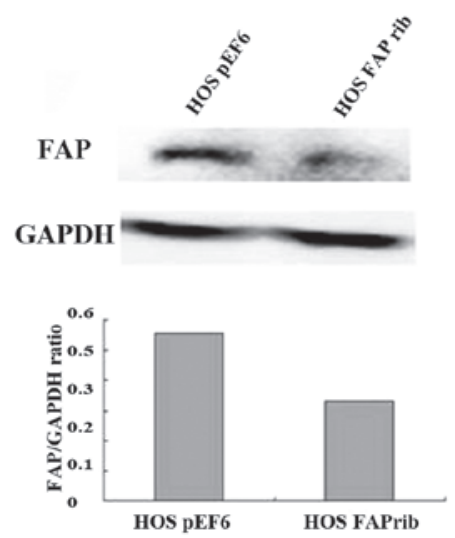

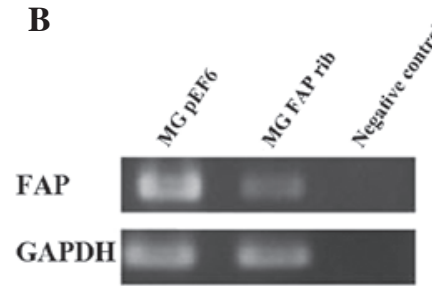

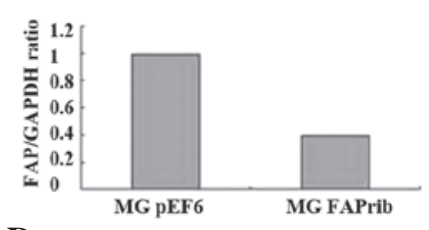

D

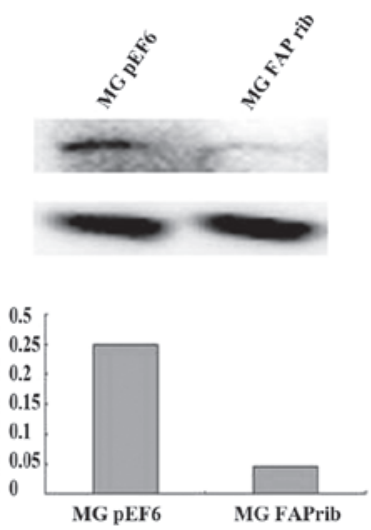

E

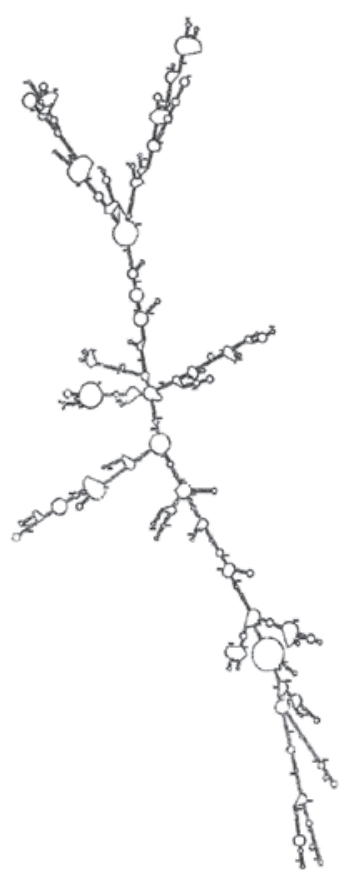

Figure 2. Knockdown of FAP in human osteosarcoma cell lines. Expression of FAP in HOS and MG-63 cell lines at the (A and B) cDNA level, as detected by polymerase chain reaction and $(\mathrm{C}$ and $\mathrm{D})$ protein level, as detected by western blot analysis. The level of FAP was significantly lower in the knockdown cells compared with their pEF controls. (E) The secondary structure of FAP mRNA was used to design the anti-FAP ribozyme. FAP, fibroblast activation protein.

A

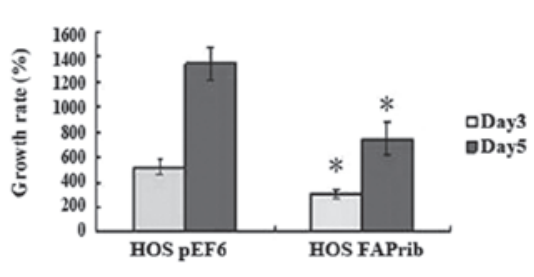

C

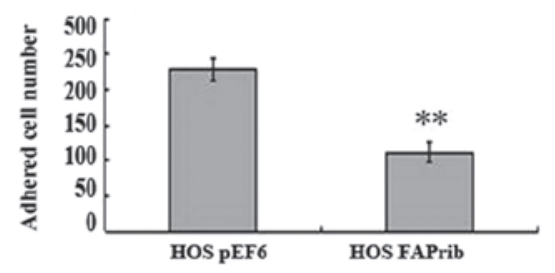

E

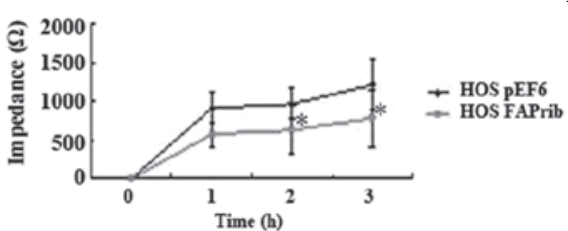

B

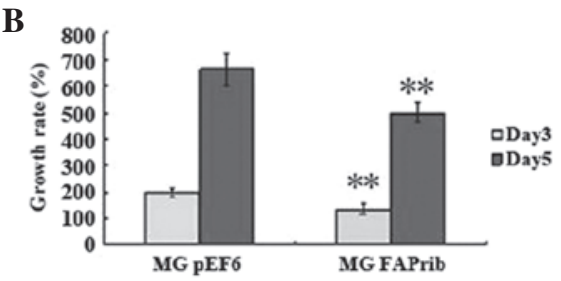

D

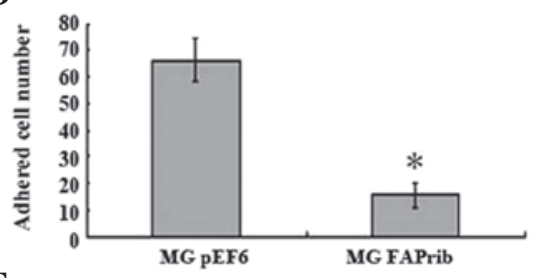

$\mathbf{F}$

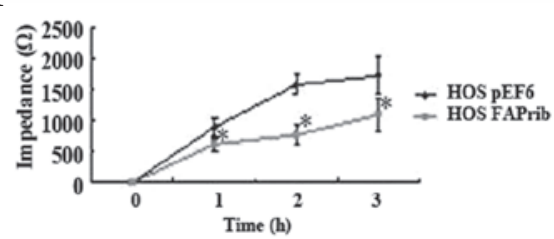

Figure 3. Cellular function tests of FAP in osteosarcoma cell lines. (A and B) Knockdown of FAP significantly reduced cell growth. (C and D) $I n$ vitro cell matrix adhesion assays were performed to assess the effect of FAP on the adhesiveness of osteosarcoma cells. (E and F) Knockdown of FAP significantly reduced cell adhesion, detected using an electric cell-substrate impedance sensing model system. FAP, fibroblast activation protein.

in OS cells, a 45-min period in vitro Matrigel adhesion assay and an ECIS assay were used. Cells adhering to the artificial Matrigel basement membrane were counted. Notably, the loss of FAP resulted in low adherence to the Matrigel in HOS and MG-63 cells ( HOS $^{\text {FAPrib }}$ vs. HOS $^{\mathrm{pEF} 6}: 111.0 \pm 15.0$ vs. $227.3 \pm 15.6$, $\mathrm{P}=0.009$; and $\mathrm{MG}^{\mathrm{FAPrib}}$ vs. $\mathrm{MG}^{\mathrm{pEF} 6}: 15.5 \pm 4.4$ vs. $66.2 \pm 8.1$, 
A

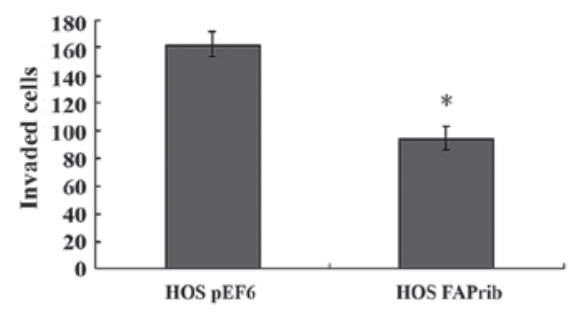

C

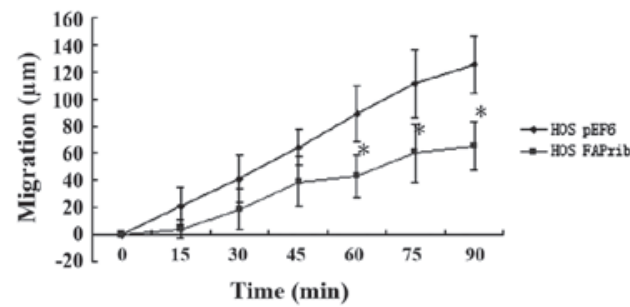

$\mathbf{E}$

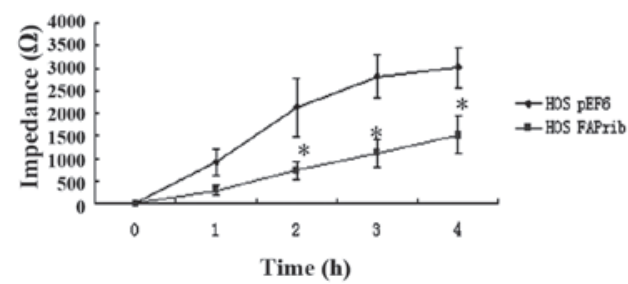

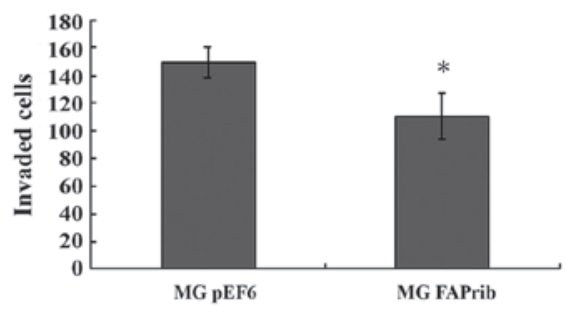

D

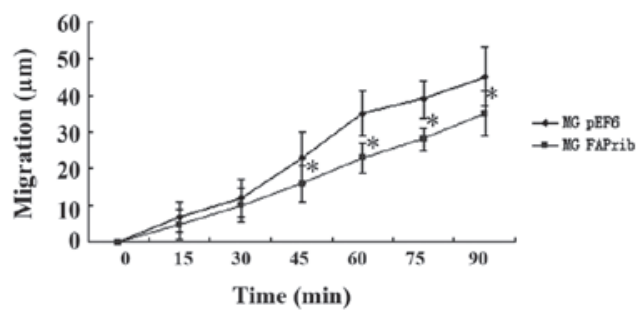

F

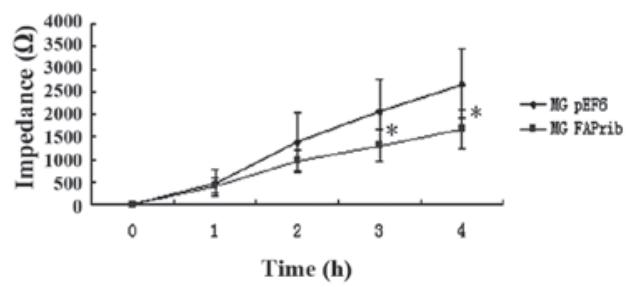

Figure 4. Knockdown of FAP decreases cell invasion, migration and motility in osteosarcoma cell lines using an electric cell-substrate impedance sensing model system. Knockdown of FAP significantly decreased cell (A and B) invasion, (C and D) migration in vitro and (E and F) motility. FAP, fibroblast activation protein.

$\mathrm{P}=0.025$; Fig. 3C and D). In the attachment assay detected by ECIS, the same tendency was observed where knockdown cells showed a low adherence compared with their control cells following seeding for $1-3 \mathrm{~h}\left(\mathrm{HOS}^{\mathrm{FAPrib}} \mathrm{vs.} \mathrm{HOS}^{\mathrm{pEF}}, \mathrm{P}<0.05\right.$ at 2 and $3 \mathrm{~h}$ after seeding; and $\mathrm{MG}^{\mathrm{FAPrib}}$ vs. $\mathrm{MG}^{\mathrm{pEF}}, \mathrm{P}<0.05$ at 1,2 and $3 \mathrm{~h}$ after seeding; Fig. 3E and F).

Knockdown of FAP decreases cell invasion. The FAP-knockdown cells exhibited a relatively lower invasive capability than their control cells in the HOS and MG-63 cell lines $\left(\mathrm{HOS}^{\mathrm{FAPrib}}\right.$ vs. $\mathrm{HOS}^{\mathrm{p} \mathrm{EF} 6}$ : $95.0 \pm 8.5$ vs. $162.3 \pm 8.8, \mathrm{P}=0.013$; and $\mathrm{MG}^{\mathrm{FAPrib}}$ vs. $\mathrm{MG}^{\mathrm{pEF}}$ : $110.7 \pm 16.2$ vs. $150.2 \pm 11.3, \mathrm{P}=0.034$; Fig. 4A and B).

Knockdown of FAP influences cell motility. The wounding assay compared the migration capabilities of OS cells between FAP-knockdown and control cells. The migration of HOS and MG-63 cells was reduced when FAP was absent during a 90 min incubation after the wounding $\left(\operatorname{HOS}^{\mathrm{FAPrib}} \mathrm{vs.} \mathrm{HOS}^{\mathrm{EFF}}\right.$, $\mathrm{P}<0.05$ after $60 \mathrm{~min}$; and $\mathrm{MG}^{\mathrm{FAPrib}}$ vs. $\mathrm{MG}^{\mathrm{pEF} 6}, \mathrm{P}<0.05$ after 45 min; Fig. 4C and D). The effect of FAP expression on cell motility was also assessed using an ECIS assay. Following wounding at $10 \mathrm{~h}$, the record of impedance and resistance of the cell layer also showed the same result as the wounding assay, which was that FAP influenced cell motility ( $\mathrm{HOS}^{\mathrm{FAPrib}}$ vs. $\mathrm{HOS}^{\mathrm{PEF}}, \mathrm{P}<0.05$ at 2,3 and $4 \mathrm{~h}$ after wounding; and $\mathrm{MG}^{\mathrm{FAP} \text { rib }}$ vs. $\mathrm{MG}^{\mathrm{pEF}}, \mathrm{P}<0.05$ at 3 and $4 \mathrm{~h}$ after wounding; Fig. 4E and F).

\section{Discussion}

FAP has been intensively investigated as a potential diagnostic or therapeutic target since it is overexpressed by activated stromal fibroblasts in malignant tumors and is absent in normal adult tissues and benign tumors (23-26). Since its identification, a number of previous studies have analyzed the localization and expression of this protease in diverse malignancies (27). FAP and DPP-IV expression is also found in bone sarcomas (5). However, the role of FAP in tumorigenesis and tumor growth, invasion and metastasis, as well as the exact molecular mechanisms, remain unknown. There is a clear discrepancy between FAP function in tumor promotion and suppression $(12,28-30)$. Previously, Santos et al (26) showed that targeted gene disruption or pharmacological inhibition of FAP proteinase activity reduces the tumor growth in mouse models of lung and colon cancer. By contrast, other studies have suggested that FAP has tumor-suppressive activity $(30,31)$. In the current study, the gene expression of FAP was knocked down through a hammerhead ribozyme transgene and the differences in the cellular functions between the knockdown cells and their controls were observed. The results of the current study indicated that knockdown of FAP markedly reduces the ability of cell growth, matrix adhesion, migration and invasion in MG-63 and HOS cell lines compared with the control cells.

The cancer-specific distribution of FAP makes it a novel therapeutic target in cancer treatment. While the function of FAP within malignancies remains poorly understood, efforts 
have been made to assess FAP as a therapeutic target, inhibiting its proteinase activity. FAP is transiently expressed in specific fetal mesenchymal tissues and is also expressed in certain disorders associated with activated stroma, including wound healing, rheumatoid arthritis, osteoarthritis, cirrhosis and pulmonary fibrosis $(5,27,32)$. The effect of FAP on cellular functions and corresponding implications in bone development and remodeling remain poorly understood. The present study examined the function of FAP in OS cells and the implication in the disease progression. FAP is considered to promote tumor cell growth and proliferation (33). Chen et al (34) previously reported that FAP increases the invasion, proliferation and migration of ovarian cancer cells. The results of the present study revealed that bone sarcoma cell lines express FAP. The knockdown of FAP markedly decreases the in vitro growth, adhesion, migration and invasion of the OS cells.

FAP influences OS cells and may play a role in OS tumor progression and metastasis. Further investigation is likely to shed light on the relevant diagnostic and therapeutic potential of FAP in OS.

\section{Acknowledgements}

Dr L. Ding was a recipient of the Cardiff University China Medical Scholarship, and the authors would like to thank the Albert Hung Foundation and Cancer Research Wales for supporting the study.

\section{References}

1. Hayden JB and Hoang BH: Osteosarcoma: basic science and clinical implications. Orthop Clin North Am 37: 1-7, 2006.

2. Henry LR, Lee HO, Lee JS, et al: Clinical implications of fibroblast activation protein in patients with colon cancer. Clin Cancer Res 13: 1736-1741, 2007.

3. Javidroozi M, Zucker S and Chen WT: Plasma seprase and DPP4 levels as markers of disease and prognosis in cancer. Dis Markers 32: 309-320, 2012.

4. Chen SJ and Jiaang WT: Current advances and therapeutic potential of agents targeting dipeptidyl peptidases-IV, -II, 8/9 and fibroblast activation protein. Curr Top Med Chem 11: 1447-1463, 2011.

5. DohiO,Ohtani H,Hatori M,etal:Histogenesis-specific expression of fibroblast activation protein and dipeptidylpeptidase-IV in human bone and soft tissue tumours. Histopathology 55: 432-440, 2009

6. Rettig WJ, Garin-Chesa P, Beresford HR, Oettgen HF, Melamed MR and Old LJ: Cell-surface glycoproteins of human sarcomas: differential expression in normal and malignant tissues and cultured cells. Proc Natl Acad Sci USA 85: 3110-3114, 1988.

7. Ghersi G, Zhao Q, Salamone M, Yeh Y, Zucker S and Chen WT: The protease complex consisting of dipeptidyl peptidase IV and seprase plays a role in the migration and invasion of human endothelial cells in collagenous matrices. Cancer Res 66: 4652-4661, 2006.

8. Cohen SJ, Alpaugh RK, Palazzo I, et al: Fibroblast activation protein and its relationship to clinical outcome in pancreatic adenocarcinoma. Pancreas 37: 154-158, 2008.

9. Goscinski MA, Suo ZH, Nesland JM, et al: Seprase, dipeptidyl peptidase IV and urokinase-type plasminogen activator expression in dysplasia and invasive squamous cell carcinoma of the esophagus. A study of 229 cases from Anyang Tumor Hospital, Henan Province, China. Oncology 75: 49-59, 2008.

10. Keane FM, Nadvi NA, Yao TW and Gorrell MD: Neuropeptide Y, B-type natriuretic peptide, substance $\mathrm{P}$ and peptide $\mathrm{YY}$ are novel substrates of fibroblast activation protein-alpha. FEBS J 278: 1316-1332, 2011
11. Kennedy A, Dong H, Chen D and Chen WT: Elevation of seprase expression and promotion of an invasive phenotype by collagenous matrices in ovarian tumor cells. Int J Cancer 124: 27-35, 2009.

12. Kraman M, Bambrough PJ, Arnold JN, et al: Suppression of antitumor immunity by stromal cells expressing fibroblast activation protein-alpha. Science 330: 827-830, 2010.

13. Yi YM, Zhang G, Zeng J, et al: A new tumor vaccine: FAPtau-MT elicits effective antitumor response by targeting indolamine2,3-dioxygenase in antigen presenting cells. Cancer Biol Ther 11: 866-873, 2011.

14. Sarto-Jackson I, Milenkovic I, Smalla KH, et al: The cell adhesion molecule neuroplastin-65 is a novel interaction partner of gamma-aminobutyric acid type A receptors. J Biol Chem 287: 14201-14214, 2012.

15. Danilova N: The evolution of adaptive immunity. Adv Exp Med Biol 738: 218-235, 2012.

16. Liu C, Lewis CM, Lou Y, et al: Agonistic antibody to CD40 boosts the antitumor activity of adoptively transferred $\mathrm{T}$ cells in vivo. J Immunother 35: 276-282, 2012.

17. Kikuchi S, Iwai M, Sakurai-Yageta M, et al: Expression of a splicing variant of the CADM1 specific to small cell lung cancer. Cancer Sci 103: 1051-1057, 2012.

18. Lee G, Cheung AP, Ge B, et al: CA215 and GnRH receptor as targets for cancer therapy. Cancer Immunol Immunother 61: 1805-1817, 2012.

19. Jiang WG, Hiscox S, Hallett MB, Scott C, Horrobin DF and Puntis MC: Inhibition of hepatocyte growth factor-induced motility and in vitro invasion of human colon cancer cells by gamma-linolenic acid. Br J Cancer 71: 744-752, 1995.

20. Estecha A, Aguilera-Montilla N, Sánchez-Mateos P and Puig-Kröger A: RUNX3 regulates intercellular adhesion molecule 3 (ICAM-3) expression during macrophage differentiation and monocyte extravasation. PLoS One 7: e33313, 2012.

21. Fujita-Hamabe W and Tokuyama S: The involvement of cleavage of neural cell adhesion molecule in neuronal death under oxidative stress conditions in cultured cortical neurons. Biol Pharm Bull 35: 624-628, 2012.

22. Meeusen JW, Klein CJ, Pirko I, et al: Potassium channel complex autoimmunity induced by inhaled brain tissue aerosol. Ann Neurol 71: 417-426, 2012.

23. Christiansen VJ,Jackson KW,Lee KN, Downs TD and McKeePA: Targeting inhibition of fibroblast activation protein-alpha and prolyl oligopeptidase activities on cells common to metastatic tumor microenvironments. Neoplasia 15: 348-358, 2013.

24. Hayward SW: Preclinical assessment of fibroblast activation protein as a target for antitumor therapy. Future Oncol 6: 347-349, 2010.

25. Puré E: The road to integrative cancer therapies: emergence of a tumor-associated fibroblast protease as a potential therapeutic target in cancer. Expert Opin Ther Targets 13: 967-973, 2009.

26. Santos AM, Jung J, Aziz N, Kissil JL and Puré E: Targeting fibroblast activation protein inhibits tumor stromagenesis and growth in mice. J Clin Invest 119: 3613-3625, 2009.

27. Liu R, Li H, Liu L, et al: Fibroblast activation protein: A potential therapeutic target in cancer. Cancer Biol Ther 13: 123-129, 2012.

28. Cheng JD, Valianou M, Canutescu AA, et al: Abrogation of fibroblast activation protein enzymatic activity attenuates tumor growth. Mol Cancer Ther 4: 351-360, 2005.

29. Scanlan MJ, Raj BK, Calvo B, et al: Molecular cloning of fibroblast activation protein alpha, a member of the serine protease family selectively expressed in stromal fibroblasts of epithelial cancers. Proc Natl Acad Sci USA 91: 5657-5661, 1994.

30. Wesley UV, Albino AP, Tiwari S and Houghton AN: A role for dipeptidyl peptidase IV in suppressing the malignant phenotype of melanocytic cells. J Exp Med 190: 311-322, 1999.

31. Ramirez-Montagut T, Blachere NE, Sviderskaya EV, et al: FAPalpha, a surface peptidase expressed during wound healing, is a tumor suppressor. Oncogene 23: 5435-5446, 2004.

32. Bauer S, Jendro MC, Wadle A, et al: Fibroblast activation protein is expressed by rheumatoid myofibroblast-like synoviocytes. Arthritis Res Ther 8: R171, 2006.

33. Goodman JD, Rozypal TL and KellyT: Seprase, a membranebound protease, alleviates the serum growth requirement of human breast cancer cells. Clin Exp Metastasis 20: 459-470, 2003.

34. Chen H, Yang WW, Wen QT, Xu L and Chen M: TGF-beta induces fibroblast activation protein expression; fibroblast activation protein expression increases the proliferation, adhesion, and migration of HO-8910PM [corrected]. Exp Mol Pathol 87: 189-194, 2009. 